\title{
Treatment satisfaction with pharmaceutical interventions in Japanese adults with osteoarthritis and chronic knee pain: an analysis of a web-based survey
}

This article was published in the following Dove Press journal:

Clinical Interventions in Aging

\author{
Kaname Ueda' \\ Nao Sasaki² \\ Amir Goren ${ }^{3}$ \\ Shawna R Calhoun ${ }^{4}$ \\ Katsuhiro Shinjo ${ }^{5}$ \\ Hiroyuki Enomoto ${ }^{5}$ \\ Takeshi Muneta ${ }^{6}$ \\ 'Health Outcomes/Health Technology \\ Assessment/Real World Evidence, \\ Eli Lilly Japan, Kobe, Japan; ${ }^{2}$ Bio- \\ Medicines, Medicines Development \\ Unit, Eli Lilly Japan, Kobe, Japan; \\ ${ }^{3}$ Health Outcomes, Kantar Health, \\ New York, NY, USA; ${ }^{4}$ Health \\ Outcomes, Kantar Health, Horsham, \\ PA, USA; ${ }^{5}$ Bio-Medicines, Medicines \\ Development Unit, Eli Lilly Japan, \\ Tokyo, Japan; ${ }^{6}$ Department of \\ Orthopaedic Surgery, National \\ Disaster Medical Center, Tokyo, Japan
}

Correspondence: Kaname Ueda Health Outcomes/Health Technology Assessment/Real World Evidence, Eli Lilly Japan, 5-I-28 Isogamidori, Chuo-ku, Kobe, Japan

$\mathrm{Tel}+81782429519$

Fax +81782429502

Email ueda_kaname@lilly.com
Purpose: Patient satisfaction is an important outcome in successful osteoarthritis (OA) treatment. The aim of this study was to evaluate treatment satisfaction for medication (TSM) in people with knee OA (KOA), identify the factors predictive of treatment satisfaction, and describe the burden of illness.

Patients and methods: This cross-sectional, patient-reported study used an Internet-based survey and analyzed responses of respondents with KOA $(\mathrm{N}=400)$ on characteristics including pain sites and levels (including pain ratings using the Numerical Rating Scale and Short-Form McGill Pain Questionnaire), treatment satisfaction (Global, Effectiveness, and Convenience scores) based on the Treatment Satisfaction Questionnaire for Medication (TSQM-9), and quality of life (QoL; based on the Arthritis Impact Measurement Scale 2-Short Form). Respondents with only KOA ( $\mathrm{n}=237)$ were compared with those having KOA and additional painful sites $(\mathrm{KOA}+$; $=163$ ). Factors predicting TSM were identified using multivariable linear regression analyses.

Results: Respondents with KOA were more likely to report intermittent pain for 3 months or more compared with those with KOA+ $(58.6 \%$ vs $48.5 \%$, respectively; $P=0.044)$, while those with KOA+ were more likely to report consistent pain for 3 months or more $(P=0.022)$. Respondents with $\mathrm{KOA}+$ also had more difficulty due to their knee pain while sleeping $(P=0.022)$ and resting $(P=0.015)$. Reported TSM did not differ significantly across KOA vs KOA+ groups, with both groups reporting low satisfaction; all domains of QoL were worse for those with KOA+. Knee pain reduction by medication predicted higher satisfaction across domains, while lower pre-medication pain and post-medication pain matching expectations predicted higher TSQM-9 Global and Effectiveness scores.

Conclusion: Medication treatment satisfaction rates were low among Japanese respondents with KOA. Given that lower pain, greater pain reduction post-medication, and meeting pain management expectations were predictive of higher satisfaction, treatment strategies that can better address pain may prove beneficial for overall patient satisfaction.

Keywords: quality of life, AIMS2-SF, SF-MPQ, TSQM-9, knee osteoarthritis

\section{Introduction}

Osteoarthritis (OA) is a chronic and progressive joint disease characterized by degeneration of joint cartilage, ${ }^{1}$ which affects $9.6 \%$ of men and $18 \%$ of women aged over 60 years worldwide. ${ }^{2}$ OA can affect single or multiple joints, causing pain of varying degrees, swelling, stiffness, restriction of movement, and in extreme cases even 
permanent disability, with corresponding impact on overall QoL and functionality. ${ }^{1,3}$ It can be caused by aging, genetic factors, joint misalignment, obesity, sex (ie, women are at greater risk), occupation, injury, loss of muscle strength, and the presence of comorbidities such as diabetes and metabolic disorders, ${ }^{4}$ with the latter being implicated in Japanese patients with $\mathrm{KOA}^{3}$

Effective clinical management of KOA, comprising both pharmacological and non-pharmacological modalities, aims to relieve pain, maintain or improve joint function, and delay/ prevent disease progression. ${ }^{5}$ Hence, patient satisfaction assessment is crucial to evaluate the effectiveness of treatment in KOA. Pain alleviation and treatment satisfaction with pharmacological, ${ }^{6}$ non-pharmacological, ${ }^{7}$ and surgical approaches ${ }^{8}$ have been reported. Although treatment satisfaction outcomes for a particular modality conducted in Western countries should be extrapolated with caution to Japanese patients due to differences in the outcome measurement methods, outcomes after total knee arthroplasty (TKA) were found to be nearly similar across all the studies. ${ }^{9-11}$ Predictive factors shown to be associated with TKA satisfaction were higher pre-operative Knee Society Score, ${ }^{12}$ low body-fat percentage, ${ }^{13}$ and greater pain and disability before surgery. ${ }^{14}$ However, no studies have yet been conducted to investigate predictive factors of TSM.

Elderly people aged 50 years and above often experience pain in multiple joints (median six joints), with knee pain due to KOA being the most common complaint. ${ }^{15}$ Studies of KOA and its management currently focus on single sites of pain and do not account for KOA with additional painful sites affected. ${ }^{16,17}$ Recently, OARSI has acknowledged the complexity of the OA patient population with guidelines for non-surgical treatments stratified by KOA only vs multi-joint $\mathrm{OA}$ and presence of comorbidities (ie, patients with KOA only with no comorbidities, KOA only with comorbidities, multi-joint OA with no comorbidities, and multi-joint OA with comorbidities). ${ }^{5}$ Despite guideline recommendations, studies comparing the outcomes and management strategies of people with KOA in Japan experiencing multiple sites of pain vs single sites are currently lacking. In order to address these knowledge gaps, this study aimed to evaluate TSM among Japanese respondents with only KOA (could be either one or both knees) and those with additional painful sites $(\mathrm{KOA}+)$, aligning with the OARSI guideline differentiation. This study also aimed to identify additional factors predictive of TSM and to describe the burden of illness associated with $\mathrm{KOA}$ vs $\mathrm{KOA}+$. A web-based survey format was chosen in order to obtain a sizeable and relatively diverse (including geographically diverse) sample of Japanese patients with KOA, such that the results could be generalized to the broader population.

\section{Patients and methods Subjects}

This cross-sectional, Internet-based, self-reported survey (fielded in March 2017) in Japan included respondents from the Japan National Health and Wellness Survey, as well as members of the Lightspeed Research patient panel. These respondents were sent e-mail invitations, and they were included only if they were 50 years old or older, self-reported a diagnosis of OA of at least one knee by a physician (among several irrelevant conditions, some of which served as exclusion criteria), reported more than 3 months of persistent OA pain, and currently received treatment for their OA pain with either prescription medications or over-the-counter pain treatment(s). Exclusion criteria were as follows: having rheumatoid arthritis or other inflammatory arthritis; history of surgical interventions for traumatic fractures; history of pyogenic knee arthritis; inherited or congenital musculoskeletal disorders; history of more than 3-month treatment or more than 1 day of hospitalization due to traffic accident; pain level higher than knee pain due to cancer; or self-reported history of paralysis, fibromyalgia, Alzheimer's Disease, dementia, or schizophrenia.

\section{Ethics approval and informed consent}

This study was reviewed and approved by Pearl Institutional Review Board (Indianapolis, IN, USA; study number: 17-KANT-142), a centralized institutional review board providing human subjects research review for non-institutional research studies in compliance with the Association for the Accreditation of Human Research Protection Programs. All participants provided their explicit online informed consent.

\section{Measures}

\section{Respondent characteristics}

The respondent characteristics measured were age, sex, employment status, marital status (married/living with partner), height, weight, smoking status, alcohol use, and CCI score, which is a weighted summary score of comorbid conditions. When both height and weight were reported, BMI was calculated.

\section{OA characteristics}

Locations of painful sites were obtained through the screening and main questionnaires. In the former, respondents were 
reminded that they had previously reported having been diagnosed with OA by a health care provider; they were then asked to select from a list the joint locations in which their physician had said they have OA (eg, jaw, neck, hands, etc). In the main questionnaire, respondents were asked to select sites in which they had experienced chronic pain (lasting/ repeating 3 months or more), and they referenced outlines of a human body (front and back) and hands (right and left) in order to make their selections; names of the affected body parts appeared when respondents hovered their cursors over the body regions: right or left jaw, shoulder, elbow, wrist, hand, hip, knee, ankle, and foot, and neck, back, and lower back. The number of painful sites (among all sites) was also assessed. Additionally, respondents were asked about any difficulty ( $1=$ not difficult to $5=$ extremely difficult) faced due to knee pain while performing the daily activities of walking, ascending and descending stairs, sleeping at night, resting during the day, and putting body weight on the knee, and their knee pain level was assessed using the NRS ( $0=$ no pain to $10=$ pain as bad as you can imagine) and the SF-MPQ (higher scores are indicative of greater pain). ${ }^{18}$ The NRS was used to assess average knee pain at multiple timepoints and the worst knee pain experienced in the past 24 hours. Change in pain level pre- to post-medication was calculated using levels reported using the NRS $(-10=$ greatest reduction to $10=$ greatest increase). The SF-MPQ was used to collect information on the sensory, affective, and evaluative dimensions of the knee pain experience by assessing the severity and types of pain (throbbing, shooting, stabbing, etc). Fifteen questions assessed various pain descriptors and two other questions in the SF-MPQ provided overall intensity scores: 1) a VAS that asked respondents to indicate where their overall pain falls on a line with "No pain" at one end and "Worst possible pain" on the other; and 2) Present Pain Intensity, for which respondents selected a categorical ranking of their present pain on a scale of $0=$ no pain to $5=$ excruciating.

\section{Treatment information}

The respondents provided information about their current treatment for OA pain management, including nonpharmacotherapy. Respondents also answered other questions regarding treatment, such as the number of times that they changed hospitals (up to 10 changes could be reported), number of different oral pain medications for OA treatment (up to 20 different drugs could be reported), number of times these oral pain medications were changed (up to 20 changes were reportable), and the number of times new oral pain medications were added to their existing treatment regimen (up to 20 additions were reportable).

\section{Outcome measures}

The TSQM-9 ${ }^{19}$ was used to measure Global, Effectiveness, and Convenience satisfaction on a scale of $0-100$, with higher scores being indicative of higher satisfaction. The TSQM-9 only focused on satisfaction with the respondent's OA pain medication. The AIMS2-SF, ${ }^{20}$ a validated measure that includes 26 items, covering the domains of physical (hand, finger, arm function), symptom (arthritis pain, mobility, self-care), affect (level of tension, mood), social interaction (support from family and friends), and role (work), was used to measure arthritis-specific QoL. For each domain, a higher score (range is 0-10) is indicative of worse QoL.

\section{Statistical analyses}

All analyses were performed using SPSS 23.0 (IBM Corporation; Armonk, NY, USA). There were no missing values; "decline to answer" and "do not know" responses were included as categories in the analyses, to avoid excluding respondents from analysis.

\section{Descriptive analyses}

Demographic and clinical characteristics of respondents with $\mathrm{KOA}$ and $\mathrm{KOA}+$ were assessed using percentages and frequencies for categorical variables and using mean values and SDs for continuous variables.

\section{Bivariate analyses}

All pairwise comparisons were conducted with one-way ANOVAs for continuous/count variables or chi-squared tests for categorical variables. Respondents with KOA and $\mathrm{KOA}+$ were compared on the outcomes of treatment satisfaction and QoL. Comparisons of demographics and clinical characteristics were also used to inform covariate selection for multivariable models.

\section{Predicting treatment satisfaction}

GLMs specifying the appropriate distribution and link function, based on the outcome of interest, were used to assess each domain of TSM (continuous TSQM-9 scale scores) as a function of respondent demographics and characteristics, as well as clinical OA status and treatment. Bivariate comparisons using a dichotomous split of Global patient satisfaction (neutral/dissatisfied $[<60]$ vs satisfied $[60+]$ ) were used to inform covariate selection. Covariates that were significant (at two-tailed $P<0.05$ ) in bivariate comparisons and those 
of conceptual interest were included in the models. The interaction of age and sex was tested for each of the models predicting the various treatment satisfaction domains. Final covariates included in each of the models were age (years), female (vs male), employed (vs unemployed), current smoker (vs non-smoker and former smoker), CCI, KOA+ (vs KOA), total number of painful sites, most recent knee pain pre-medication, change in pain pre- to post-medication, pain levels post-medication matching expectations, difficulty with activities, consistent pain that continues for $\geq 3$ months, and SF-MPQ Total Score.

\section{Results}

Among the 400 respondents who met the eligibility criteria (Figure 1), bilateral knee pain was reported by more than half of the respondents (52.0\%; Figure 2). The average number of

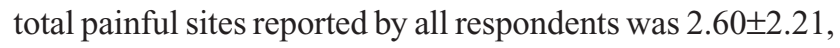
ranging from 1 to 21 sites (data not shown).

Compared with respondents with $\mathrm{KOA}+$, respondents with KOA were more frequently male (59.9\% vs $41.7 \%)$, full-time employees (34.6\% vs $25.2 \%$ ), had a different distribution of BMI (normal BMI: $55.7 \%$ vs $42.9 \%$ ), and on average had lower CCI scores ( 0.13 vs 0.31 ), all $P<0.05$ (Table 1). The proportions of respondents with $\mathrm{KOA}(51.5 \%)$ and $\mathrm{KOA}+(52.8 \%)$ reporting bilateral knee pain did not differ significantly ( $P=0.801$; Figure 2$)$. In respondents with $\mathrm{KOA}+$, the most commonly reported additional painful sites were the lower back (41.7\%), followed by the hip(s) (36.9\%), shoulder(s) (30.7\%), and neck (17.8\%). Additionally, 7.4\% of the respondents with $\mathrm{KOA}+$ reported having back pain

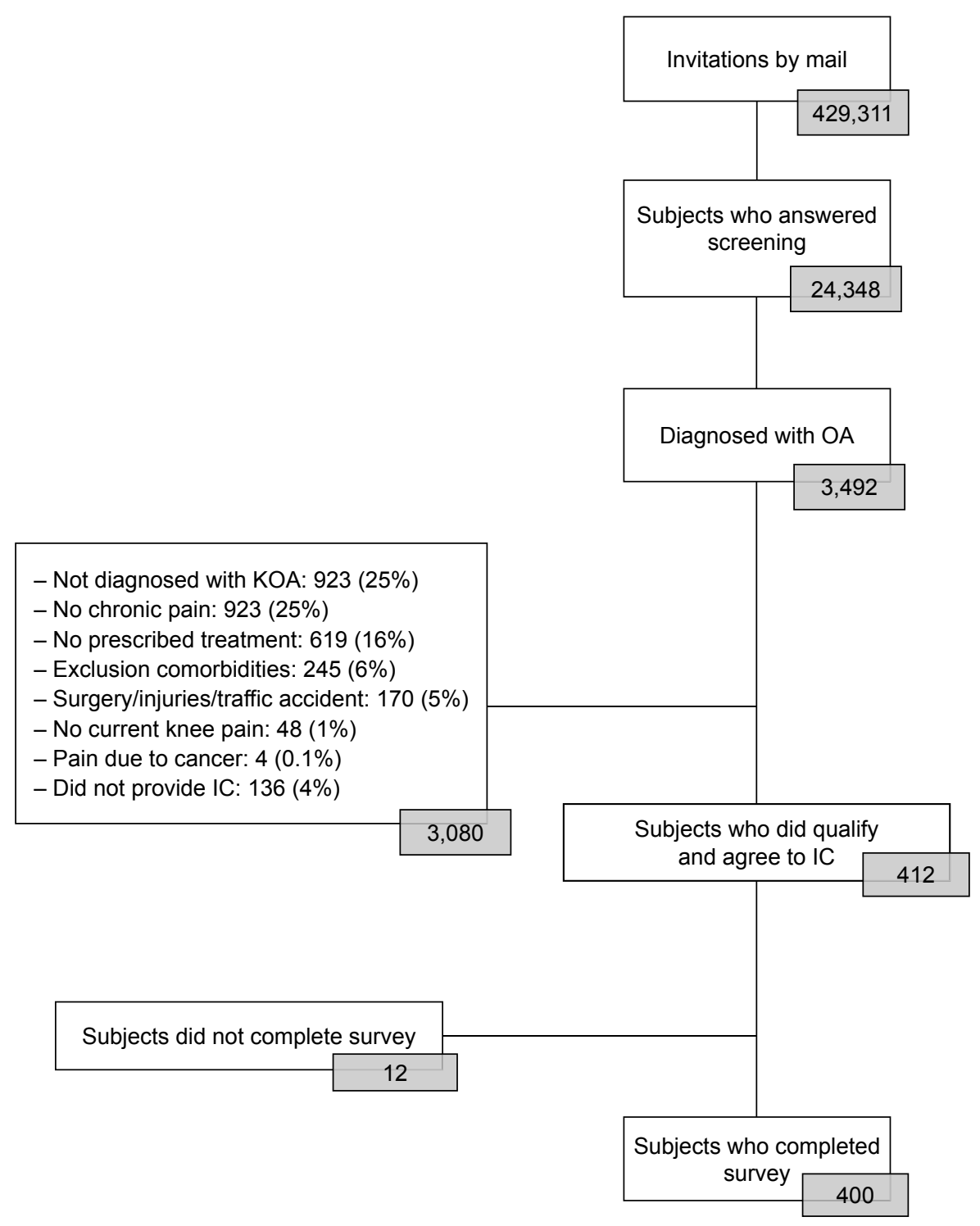

Figure I Flow chart of survey sampling.

Abbreviations: IC, informed consent; ICF, informed consent form; KOA, knee osteoarthritis. 


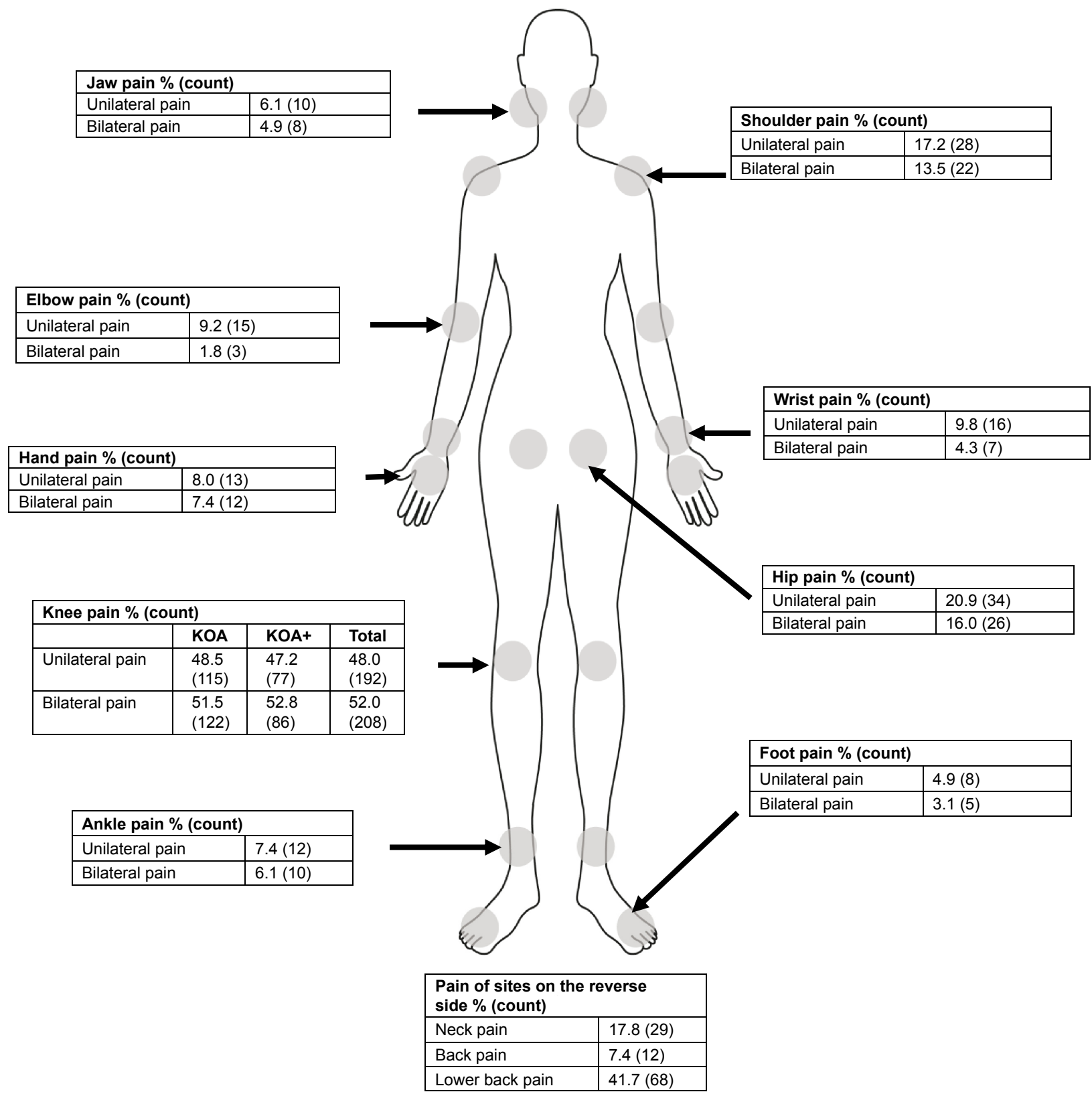

Figure 2 Pain in the major joints in respondents with KOA.

Notes: The denominator for sites other than the knee is respondents with additional painful sites (KOA+, $\mathrm{n}=163$ ). By definition, respondents with $\mathrm{KOA}$ only (KOA, $\mathrm{n}=237$ ) cannot have pain in sites other than the knee.

Abbreviations: KOA, knee osteoarthritis; $\mathrm{KOA}+$, knee osteoarthritis with additional painful sites.

(Figure 2). Respondents with KOA more frequently reported having pain that comes and goes for 3 months or longer, compared with respondents with KOA+ $(58.6 \%$ vs $48.5 \%$, $P=0.044$; Table 2). Respondents with KOA+ more frequently reported having pain that is consistent and continues for 3 months or longer compared with KOA respondents (53.4\% vs $41.8 \%, P=0.022$; Table 2 ).

$\mathrm{KOA}$ and $\mathrm{KOA}+$ respondents differed $(P<0.001)$ on the number of years since diagnosis with $\mathrm{OA}$ (less than 1 year, 1-3 years, 4-6 years, 7-10 years, 11 or more years). Respondents with KOA+ also most frequently reported being diagnosed 4-6 years prior (35.0\%), whereas respondents with KOA most frequently reported being diagnosed $1-3$ years prior (28.3\%; Table 2). Additionally, respondents with $\mathrm{KOA}+$ reported greater mean difficulty with night time sleeping ( 1.52 vs $1.33, P=0.022)$ and resting during the day (1.37 vs $1.21, P=0.015$ ) due to their knee pain, compared with respondents with KOA (Table 2). Worst knee pain in the past 24 hours and average knee pain levels on the NRS for the past 24 hours, past week, and past month were not significantly different between the two groups. Comparisons of reported pre- and post-medication pain levels, as well as 
Table I Sociodemographic and general health characteristics of the study sample

\begin{tabular}{|c|c|c|c|}
\hline Characteristics & $\begin{array}{l}\text { KOA } \\
(\mathrm{N}=237)\end{array}$ & $\begin{array}{l}\text { KOA+ } \\
(\mathrm{N}=163)\end{array}$ & $P$-value \\
\hline \multicolumn{4}{|l|}{ Age (mean $\pm S D)$} \\
\hline Years & $63.1 \pm 7.2$ & $62.9 \pm 8.0$ & 0.836 \\
\hline \multicolumn{4}{|l|}{ Sex \% (n) } \\
\hline Male & $59.9(142)$ & $41.7(68)$ & $<0.001$ \\
\hline Female & $40.1(95)$ & $58.3(95)$ & \\
\hline \multicolumn{4}{|l|}{ Employment status \% (n) } \\
\hline Employed full-time & $34.6(82)$ & $25.2(4 I)$ & 0.044 \\
\hline Self-employed & $6.3(15)$ & $7.4(12)$ & 0.686 \\
\hline Employed part-time & $11.0(26)$ & $13.5(22)$ & 0.445 \\
\hline Homemaker & $19.8(47)$ & $28.8(47)$ & 0.037 \\
\hline Retired & $16.0(38)$ & $15.3(25)$ & 0.851 \\
\hline Long-term disability & $0.0(0)$ & $0.6(1)$ & 0.227 \\
\hline Short-term disability & $0.0(0)$ & $0.0(0)$ & - \\
\hline Not employed, but looking for work & $2.1(5)$ & $1.8(3)$ & 0.850 \\
\hline Not employed and not looking for work & $12.7(30)$ & $11.7(19)$ & 0.764 \\
\hline \multicolumn{4}{|l|}{ Marital status \% (n) } \\
\hline Married/living with partner & $74.7(177)$ & $74.2(121)$ & 0.919 \\
\hline \multicolumn{4}{|l|}{ Body mass index \% (n) } \\
\hline Underweight & $0.8(2)$ & $3.7(6)$ & 0.019 \\
\hline Normal & $55.7(132)$ & $42.9(70)$ & \\
\hline Overweight & $22.8(54)$ & $22.7(37)$ & \\
\hline Obese & $9.3(22)$ & $11.0(18)$ & \\
\hline Declined to answer & II.4 (27) & $19.6(32)$ & \\
\hline \multicolumn{4}{|l|}{ Smoking status \% (n) } \\
\hline Current smoker & $17.7(42)$ & $12.9(2 \mid)$ & 0.192 \\
\hline \multicolumn{4}{|l|}{ Use of alcohol \% (n) } \\
\hline Current alcohol drinker & $75.5(179)$ & $71.8(117)$ & 0.401 \\
\hline $\mathrm{CCl}$ score (mean $\pm \mathrm{SD})$ & $0.13 \pm 0.5$ & $0.3 I \pm 0.8$ & 0.010 \\
\hline
\end{tabular}

Abbreviations: $\mathrm{CCl}$, Charlson comorbidity index; $\mathrm{KOA}$, knee osteoarthritis; $\mathrm{KOA}+$, knee osteoarthritis with additional painful sites.

expected pain levels post-medication, were not significant (Table 2). Additionally, the proportion of respondents whose expected post-medication pain matched reality did not differ significantly between respondents with $\mathrm{KOA}$ and $\mathrm{KOA}+$ (68.4\% vs $61.3 \%, P=0.148)$.

Using the SF-MPQ, mean reported pain intensity total, sensory, and affective scores were significantly higher in respondents with $\mathrm{KOA}+$ compared with those with $\mathrm{KOA}$ (8.87 vs $6.77, P=0.003 ; 7.23$ vs $5.89, P=0.014 ; 1.64$ vs $0.88, P<0.001$, respectively; Table 3$)$. Respondents with $\mathrm{KOA}+$ more often reported using oral medications and exercise therapy as one of their current treatments than did respondents with $\mathrm{KOA}(76.7 \%$ vs $60.3 \%, P=0.001 ; 35.0 \%$ vs $21.1 \%, P=0.002$, respectively; Table 4$)$. The majority of respondents among both $\mathrm{KOA}$ and $\mathrm{KOA}+$ groups used non-steroidal anti-inflammatory drugs $(73.4 \%$ vs $79.2 \%$, respectively). However, there were no significant differences in the type of oral medication used. The type of health care provider currently managing respondents' OA also did not differ significantly $(P=0.179)$, with the majority of those with KOA (92.8\%) and KOA+ (95.1\%) being managed by an orthopedic specialist. There was also no significant difference in the frequency of health care provider visits for either pain complaints or prescription refills. Respondents with $\mathrm{KOA}$ and $\mathrm{KOA}+$ most frequently reported seeing their health care provider once a month $(30.4 \%$ and $34.4 \%$, respectively; $P=0.095$; data not shown). Respondents with $\mathrm{KOA}+$ also, on average, changed hospitals and used a greater number of different oral pain medications for OA treatment than respondents with $\mathrm{KOA}(1.40$ vs $1.01, P=0.022 ; 1.38$ vs $1.01, P<0.001$, respectively; Table 4$)$. However, the number of times oral pain medications were changed (not added) ( 0.68 vs $0.88 ; P=0.173$ ) or added ( 0.36 vs 0.45 ; $P=0.338$ ) did not differ significantly between respondents with $\mathrm{KOA}$ and $\mathrm{KOA}+$.

Reported mean QoL, as measured by the AIMS2-SF, was significantly worse for respondents with $\mathrm{KOA}+$ than respondents with KOA in all domains: physical (1.79 vs 1.38, $P=0.005)$, symptom ( 2.80 vs $2.35, P=0.021)$, affect ( 2.28 vs $1.57, P<0.001$ ), social interaction (6.28 vs $5.78, P=0.012$ ), 
Table 2 Clinical KOA characteristics

\begin{tabular}{|c|c|c|c|}
\hline Characteristics & $\begin{array}{l}\text { KOA } \\
(\mathrm{N}=237)\end{array}$ & $\begin{array}{l}\text { KOA+ } \\
(\mathrm{N}=163)\end{array}$ & P-value \\
\hline \multicolumn{4}{|l|}{ Years since diagnosis with osteoarthritis \% (n) } \\
\hline Less than I year & $16.5(39)$ & $6.1(10)$ & $<0.001$ \\
\hline I-3 years & $28.3(67)$ & $16.6(27)$ & \\
\hline 4-6 years & $24.9(59)$ & $35.0(57)$ & \\
\hline $7-10$ years & I8.I (43) & $21.5(35)$ & \\
\hline II or more years & $12.2(29)$ & $20.9(34)$ & \\
\hline \multicolumn{4}{|l|}{ Pain level (mean \pm SD) } \\
\hline Average knee pain in past 24 hours & $3.73 \pm 2.14$ & $3.81 \pm 2.13$ & 0.713 \\
\hline Worst knee pain in past 24 hours & $4.47 \pm 2.38$ & $4.63 \pm 2.45$ & 0.516 \\
\hline Average knee pain in past week & $4.35 \pm 2.35$ & $4.4 I \pm 2.36$ & 0.800 \\
\hline Average knee pain in past month & $4.59 \pm 2.37$ & $4.87 \pm 2.35$ & 0.254 \\
\hline Most recent knee pain before taking pain medication & $5.02 \pm 2.27$ & $5.43 \pm 2.27$ & 0.075 \\
\hline Most recent knee pain after taking pain medication & $3.52 \pm 2.28$ & $3.63 \pm 2.26$ & 0.639 \\
\hline Expected pain level after taking medication & $2.68 \pm 2.15$ & $2.87 \pm 2.20$ & 0.386 \\
\hline Change in pain level pre- to post-medication (mean $\pm S D$ ) & $-1.49 \pm 1.89$ & $-1.80 \pm 1.79$ & 0.107 \\
\hline Expected pain levels matched reality post-medication \% (n) & $68.4(162)$ & $61.3(100)$ & 0.148 \\
\hline \multicolumn{4}{|l|}{ Difficulty: (mean $\pm S D)$} \\
\hline Walking & $1.97 \pm 0.98$ & $2.06 \pm 1.02$ & 0.393 \\
\hline Ascending stairs & $2.36 \pm 1.04$ & $2.53 \pm 1.08$ & 0.104 \\
\hline Descending stairs & $2.78 \pm 1.06$ & $2.84 \pm 1.19$ & 0.598 \\
\hline Night time sleeping & $1.33 \pm 0.68$ & $1.52 \pm 0.90$ & 0.022 \\
\hline Resting during the day & $1.21 \pm 0.54$ & $1.37 \pm 0.79$ & 0.015 \\
\hline Putting body weight on the knee & $2.46 \pm 1.11$ & $2.63 \pm 1.21$ & 0.135 \\
\hline Total number of painful sites (mean \pm SD) & $\mathrm{I} .5 \mathrm{I} \pm 0.50$ & $4.17 \pm 2.74$ & $<0.001$ \\
\hline Pain that comes and goes for 3 months or longer \% (n) & $58.6(139)$ & $48.5(79)$ & 0.044 \\
\hline Pain that is consistent and continues for 3 months or longer \% (n) & $41.8(99)$ & $53.4(87)$ & 0.022 \\
\hline
\end{tabular}

Abbreviations: KOA, knee osteoarthritis; $\mathrm{KOA}+$, knee osteoarthritis with additional painful sites.

and role (1.18 vs $0.71, P=0.036$; Figure 3 ). Among all the domains, both the groups reported highest QoL impairment with respect to social interaction.

There were no statistically significant differences in TSQM-9 Global, Effectiveness, or Convenience scores across patient subgroups (Figure 4). Assessing TSQM-9 Global TSM on a continuous scale resulted in a mean Global score of 50.00 in those with KOA, compared with 51.18 in those with KOA+ $(P=0.521)$. TSQM-9 Effectiveness and
Convenience scores also did not differ significantly between those with KOA and KOA+ (48.38 vs 48.98, $P=0.753 ; 68.78$ vs $68.71, P=0.972$, respectively). Among all respondents, $67.5 \%$ reported TSQM-9 Global scores of 50 or below.

The interaction of age and sex was not found to be significant for the models predicting TSQM-9 Global, Effectiveness, or Convenience TSM. GLMs specifying a normal distribution were used. There were some statistically significant predictors that were common across the domains

Table 3 Type of pain by the SF-MPQ

\begin{tabular}{|c|c|c|c|}
\hline Pain score & $\begin{array}{l}\text { KOA } \\
(N=237)\end{array}$ & $\begin{array}{l}\text { KOA }+ \\
(N=163)\end{array}$ & P-value \\
\hline Total score (PRI-T) (mean $\pm S D)$ & $6.77 \pm 6.32$ & $8.87 \pm 7.77$ & 0.003 \\
\hline Sensory score (PRI-S) (mean \pm SD) & $5.89 \pm 5.09$ & $7.23 \pm 5.70$ & 0.014 \\
\hline Affective score (PRI-A) (mean \pm SD) & $0.88 \pm 1.61$ & $1.64 \pm 2.50$ & $<0.001$ \\
\hline Intensity score (VAS) (mean $\pm S D$ ) & $34.46 \pm 23.48$ & $36.67 \pm 23.34$ & 0.354 \\
\hline Present pain intensity (mean $\pm S D$ ) & $1.83 \pm 0.98$ & $2.03 \pm 1.11$ & 0.059 \\
\hline
\end{tabular}

Note: Higher SF-MPQ scores are indicative of more severe pain.

Abbreviations: KOA, knee osteoarthritis; KOA+, knee osteoarthritis with additional painful sites; PRI-A, Pain Rating Index Affective; PRI-S, Pain Rating Index Sensory; PRI-T, Pain Rating Index Total; SF-MPQ, Short-Form McGill Pain Questionnaire. 
Table 4 Health care provider and treatment characteristics

\begin{tabular}{|c|c|c|c|}
\hline Characteristics & $\begin{array}{l}\text { KOA } \\
(\mathrm{N}=237)\end{array}$ & $\begin{array}{l}\text { KOA }+ \\
(\mathrm{N}=163)\end{array}$ & $P$-value \\
\hline \multicolumn{4}{|l|}{ Current treatment of OA pain $\%(n)$} \\
\hline Oral medication & $60.3(143)$ & $76.7(125)$ & 0.001 \\
\hline Patch/ointment & $77.2(183)$ & $78.5(128)$ & 0.756 \\
\hline Intra-articular hyaluronic acid injection & $71.3(169)$ & $65.0(106)$ & 0.183 \\
\hline Intra-articular steroid injection & $8.9(21)$ & $11.0(18)$ & 0.470 \\
\hline Physical therapy (electrical therapy/hyperthermia) & $24.9(59)$ & $29.4(48)$ & 0.312 \\
\hline Exercise therapy & $21.1(50)$ & $35.0(57)$ & 0.002 \\
\hline Orthosis for medical treatment & $32.5(77)$ & $41.1(67)$ & 0.078 \\
\hline Others & $1.7(4)$ & $4.3(7)$ & 0.117 \\
\hline \multicolumn{4}{|l|}{ Current oral medication \% ( $\mathrm{n}$ ) } \\
\hline Acetaminophen & $13.3(19)$ & $8.8(\mathrm{II})$ & 0.245 \\
\hline Non-steroidal anti-inflammatory drug & $73.4(105)$ & $79.2(99)$ & 0.269 \\
\hline Opioid & $6.3(9)$ & $12(15)$ & 0.103 \\
\hline Duloxetine & $2.1(3)$ & $3.2(4)$ & 0.573 \\
\hline Over the counter & $30.1(43)$ & $22.4(28)$ & 0.156 \\
\hline Others & $9.1(13)$ & $9.6(12)$ & 0.886 \\
\hline I do not know & $9.1(13)$ & $6(4.8)$ & 0.172 \\
\hline \multicolumn{4}{|l|}{ Type of health care provider managing OA \% (n) } \\
\hline Orthopedic & $92.8(220)$ & $95.1(155)$ & 0.179 \\
\hline Rheumatism & $0.0(0)$ & $1.2(2)$ & \\
\hline General internal medicine & $1.7(4)$ & $1.8(3)$ & \\
\hline Pain clinic/anesthesiology & $3.0(7)$ & $1.2(2)$ & \\
\hline Other specialists & $2.5(6)$ & $0.6(I)$ & \\
\hline Number of times changed hospitals for osteoarthritis treatment (mean $\pm S D$ ) & $1.01 \pm 1.67$ & $1.40 \pm 1.67$ & 0.022 \\
\hline Number of different oral pain medications for $O A$ treatment (mean $\pm S D$ ) & $1.01 \pm 0.76$ & $1.38 \pm 1.13$ & $<0.001$ \\
\hline $\begin{array}{l}\text { Number of times changed (not added another medication) oral pain medications } \\
\text { for OA treatment (mean } \pm \text { SD) }\end{array}$ & $0.68 \pm 1.59$ & $0.88 \pm 1.23$ & 0.173 \\
\hline Number of times added additional oral pain medications for OA treatment (mean \pm SD) & $0.36 \pm 1.03$ & $0.45 \pm 0.78$ & 0.338 \\
\hline
\end{tabular}

Abbreviations: KOA, knee osteoarthritis; $\mathrm{KOA}+$, knee osteoarthritis with additional painful sites; OA, osteoarthritis.

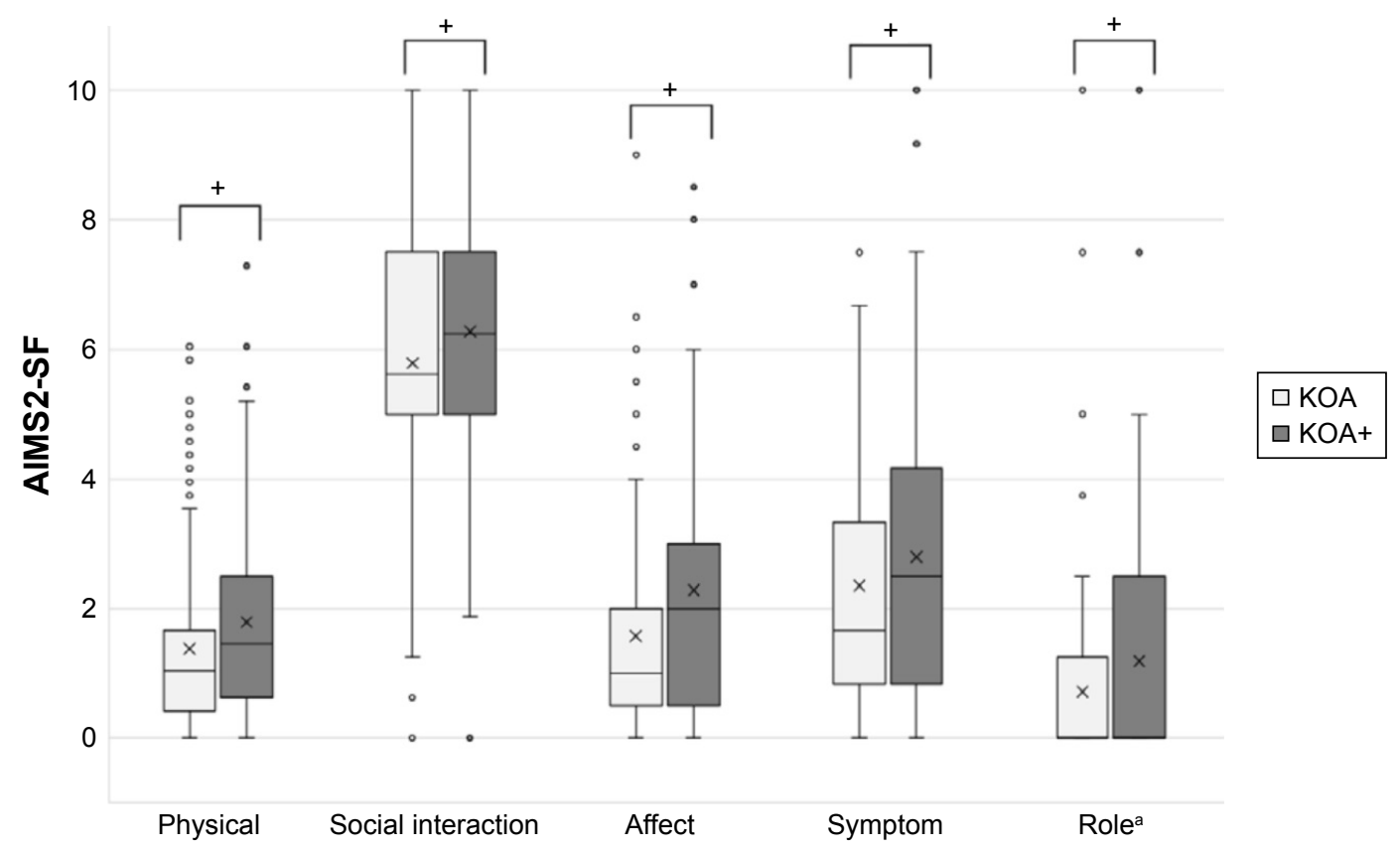

Figure 3 Box and whisker plots of AIMS2-SF scores grouped by KOA vs KOA+.

Notes: Horizontal lines represent medians. Xs represent mean values. Shaded boxes represent IQRs. Whiskers represent values ranging I.5 times IQR, while dots represent outlying values. ${ }^{a}$ Employed respondents only (KOA, $n=163 ; \mathrm{KOA}+\mathrm{n}=96$ ). + denotes KOA vs $\mathrm{KOA}+, \mathrm{P}<0.05$.

Abbreviations: AIMS2-SF, Arthritis Impact Measurement Scale 2-Short Form; IQR, interquartile range; KOA, knee osteoarthritis; KOA+, knee osteoarthritis and additional painful sites. 


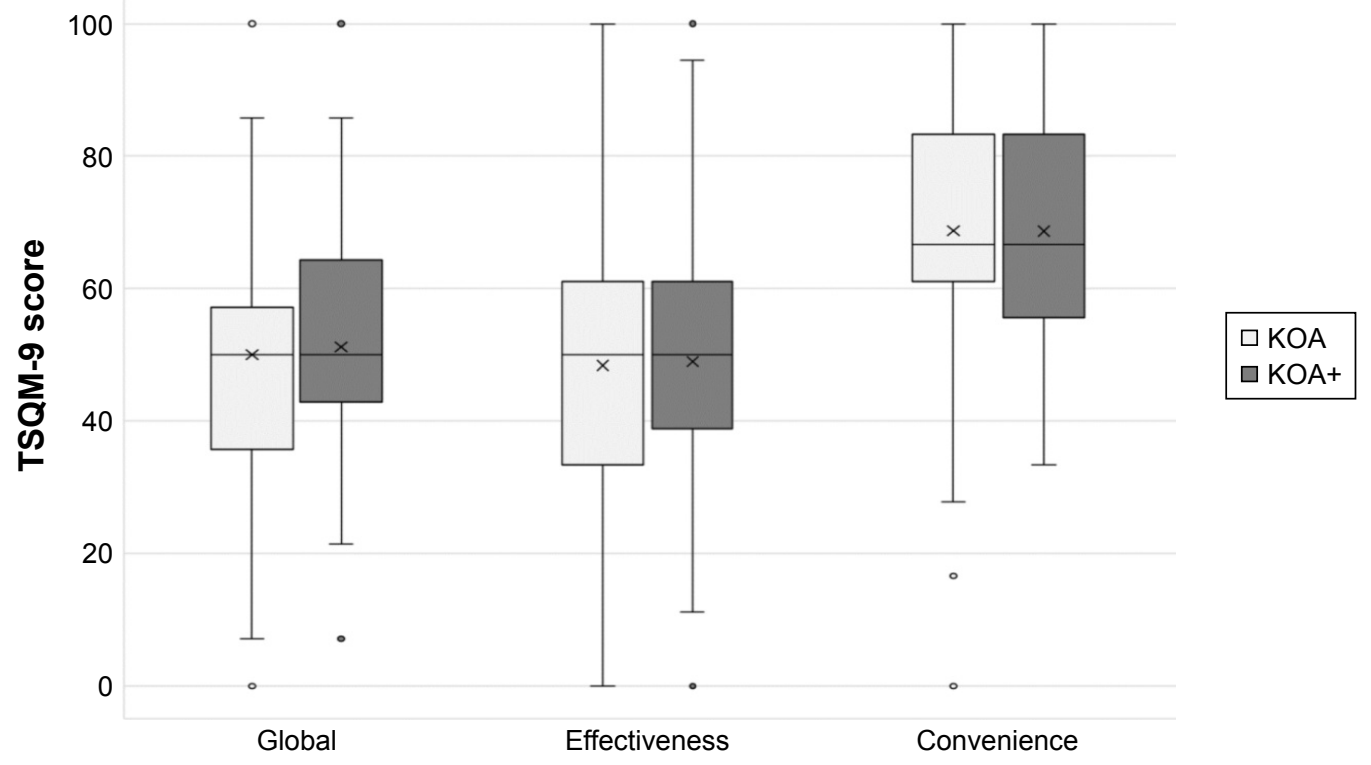

Figure 4 Box and whisker plots of TSQM-9 scores grouped by KOA vs KOA+.

Notes: Horizontal lines represent medians. Xs represent mean values. Shaded boxes represent IQRs. Whiskers represent values ranging I.5 times IQR, while dots represent outlying values.

Abbreviations: IQR, interquartile range; KOA, knee osteoarthritis; KOA+, knee osteoarthritis and additional painful sites; TSQM-9, Treatment Satisfaction Questionnaire for Medication.

of TSM. Reduction in knee pain predicted significantly higher TSQM-9 Global, Effectiveness, and Convenience Satisfaction scores. Lower pre-medication pain and expected post-medication pain matching reality predicted significantly higher TSQM-9 Global satisfaction and Effectiveness scores. Other significant predictors varied across satisfaction domains. Being employed predicted higher TSQM-9 Global satisfaction scores, while being female predicted higher TSQM-9 Effectiveness scores. Being a current smoker and having lower total pain (SF-MPQ Total Score) predicted higher TSQM-9 Convenience scores (Table 5). KOA vs KOA+ was not found to be a significant predictor of any of the domains of TSM, after controlling for other covariates.

\section{Discussion}

This study is the first exploration of real-world patient-reported data in Japanese respondents with KOA that compares TSM across respondents who reported $\mathrm{KOA}$ and $\mathrm{KOA}+$, while also identifying novel factors associated with TSM.

Treatment satisfaction is essential in OA and largely determines whether a patient continues or changes treatment. ${ }^{11}$ Across sociodemographic characteristics, employment status was found to be predictive of TSQM-9 Global treatment satisfaction, while being female predicted a higher TSQM-9 Effectiveness score. Other factors that significantly predicted higher scores in all the TSM domains were pain post-medication matching expectations, reduction in pain, and suffering from low pain levels prior to medication (as per the NRS). TSM was found to be higher in respondents with lower pain, aligning with an earlier study showing decreased pain to be associated with increased treatment efficacy and thereby patient satisfaction. ${ }^{21}$ Hence, switching treatments to achieve lower pain levels might enhance treatment satisfaction among patients with KOA. Moreover, the findings regarding pain as an important factor in predicting treatment satisfaction may be extrapolated to patients with KOA globally. In this study, respondents with $\mathrm{KOA}+$ changed hospitals more frequently and took more oral pain medications than respondents with KOA. However, the treatment approach and number of times patients switched and/or added oral pain medications were similar among the two groups, suggesting that despite $\mathrm{KOA}+$ patients switching health care providers, the medications were not added or changed. This may reflect a patient-doctor communication gap in patients with $\mathrm{KOA}+$ regarding how satisfactory their treatment regimen is.

Respondents with KOA+ in this study had consistent pain, with worse QoL than respondents with KOA. Moreover, similar to earlier research associating knee pain with pain development in multiple other sites, ${ }^{22} 40.8 \%$ of the KOA patients in the current study reported additional painful sites; the lower back, hips, shoulders, and neck were the most common. Even in patients with unilateral KOA $(n=192), 77$ 
Table 5 Predicting change in TSQM-9 scores

\begin{tabular}{|c|c|c|c|}
\hline Parameter & $\begin{array}{l}\text { Global } \\
\text { (B and } 95 \% \mathrm{Cl} \text { ) }\end{array}$ & $\begin{array}{l}\text { Effectiveness } \\
\text { (B and } 95 \% \mathrm{Cl} \text { ) }\end{array}$ & $\begin{array}{l}\text { Convenience } \\
\text { (B and } 95 \% \mathrm{Cl} \text { ) }\end{array}$ \\
\hline Age & $\begin{array}{l}0.079 \\
(-0.164 \text { to } 0.321)\end{array}$ & $\begin{array}{l}0.038 \\
(-0.164 \text { to } 0.321)\end{array}$ & $\begin{array}{l}-0.023 \\
(-0.299 \text { to } 0.252)\end{array}$ \\
\hline Female (vs male) & $\begin{array}{l}1.934 \\
(-1.357 \text { to } 5.225)\end{array}$ & $\begin{array}{l}4.190 \\
(0.993 \text { to } 7.387)^{*}\end{array}$ & $\begin{array}{l}2.418 \\
(-1.324 \text { to } 6.160)\end{array}$ \\
\hline Employed (vs unemployed) & $\begin{array}{l}4.239 \\
(0.522 \text { to } 7.955)^{*}\end{array}$ & $\begin{array}{l}1.557 \\
(-2.052 \text { to } 5.167)\end{array}$ & $\begin{array}{l}1.539 \\
(-2.686 \text { to } 5.764)\end{array}$ \\
\hline $\begin{array}{l}\text { Current smoker (vs former smoker and non- } \\
\text { smoker) }\end{array}$ & $\begin{array}{l}0.770 \\
(-3.554 \text { to } 5.094)\end{array}$ & $\begin{array}{l}0.536 \\
(-3.664 \text { to } 4.736)\end{array}$ & $\begin{array}{l}7.071 \\
(2.156 \text { to } 11.986)^{*}\end{array}$ \\
\hline $\mathrm{CCl}$ score & $\begin{array}{l}0.031 \\
(-2.239 \text { to } 2.301)\end{array}$ & $\begin{array}{l}0.097 \\
(-2.108 \text { to } 2.302)\end{array}$ & $\begin{array}{l}0.906 \\
(-1.675 \text { to } 3.486)\end{array}$ \\
\hline $\mathrm{KOA}+($ vs KOA $)$ & $\begin{array}{l}\text { I.48I } \\
(-2.425 \text { to } 5.387)\end{array}$ & $\begin{array}{l}0.128 \\
(-3.666 \text { to } 3.921)\end{array}$ & $\begin{array}{l}1.583 \\
(-2.857 \text { to } 6.022)\end{array}$ \\
\hline Total number of pain sites & $\begin{array}{l}0.538 \\
(-0.347 \text { to } 1.422)\end{array}$ & $\begin{array}{l}0.719 \\
(-0.140 \text { to } 1.578)\end{array}$ & $\begin{array}{l}-0.493 \\
(-1.498 \text { to } 0.5 \mid 3)\end{array}$ \\
\hline Most recent knee pain pre-medication & $\begin{array}{l}-1.375 \\
(-2.299 \text { to }-0.45 I)^{*}\end{array}$ & $\begin{array}{l}-1.548 \\
(-2.446 \text { to }-0.65 \mid)^{*}\end{array}$ & $\begin{array}{l}-0.696 \\
(-1.746 \text { to } 0.355)\end{array}$ \\
\hline Change in pain pre- to post-medication & $\begin{array}{l}-1.612 \\
(-2.608 \text { to }-0.616)^{*}\end{array}$ & $\begin{array}{l}-1.703 \\
(-2.670 \text { to }-0.735)^{*}\end{array}$ & $\begin{array}{l}-1.270 \\
(-2.402 \text { to }-0.138)^{*}\end{array}$ \\
\hline $\begin{array}{l}\text { Expected pain levels matched reality post- } \\
\text { medication (vs not) }\end{array}$ & $\begin{array}{l}13.959 \\
(10.444 \text { to } 17.474)^{*}\end{array}$ & $\begin{array}{l}16.068 \\
(12.654 \text { to } 19.482)^{*}\end{array}$ & $\begin{array}{l}-0.205 \\
(-4.201 \text { to } 3.790)\end{array}$ \\
\hline Mean difficulty with activities & $\begin{array}{l}-0.642 \\
(-3.442 \text { to } 2.158)\end{array}$ & $\begin{array}{l}-2.626 \\
(-5.345 \text { to } 0.094)\end{array}$ & $\begin{array}{l}-0.659 \\
(-3.842 \text { to } 2.524)\end{array}$ \\
\hline $\begin{array}{l}\text { Consistent pain that continues (vs pain that only } \\
\text { comes and goes) } \geq 3 \text { months }\end{array}$ & $\begin{array}{l}-1.438 \\
(-4.870 \text { to } 1.993)\end{array}$ & $\begin{array}{l}-0.815 \\
(-4.148 \text { to } 2.518)\end{array}$ & $\begin{array}{l}\text { I.823 } \\
(-2.078 \text { to } 5.724)\end{array}$ \\
\hline SF-MPQ: Total Score & $\begin{array}{l}-0.225 \\
(-0.495 \text { to } 0.044)\end{array}$ & $\begin{array}{l}-0.186 \\
(-0.447 \text { to } 0.076)\end{array}$ & $\begin{array}{l}-0.353 \\
(-0.659 \text { to }-0.047)^{*}\end{array}$ \\
\hline
\end{tabular}

Notes: $* P<0.05$. Presented are beta coefficients (B) and $95 \%$ Cls from normal generalized linear models predicting each TSQM-9 scale as a function of all variables shown. Beta coefficients represent change in satisfaction associated with a one-unit change in each corresponding predictor.

Abbreviations: $\mathrm{CCl}$, Charlson comorbidity index; KOA, knee osteoarthritis; SF-MPQ, McGill Pain Questionnaire-Short Form; TSQM-9, Treatment Satisfaction Questionnaire for Medication.

(40.1\%) were categorized as KOA+ (Figure 2). As knee and hip OA have been associated with increased risk of cardiovascular events, ${ }^{23}$ and given evidence in this study showing that persons with KOA commonly have other joints affected, physicians should assess and treat not just the most painful site, but all affected joints as well.

Pain - the most common symptom reported by patients with KOA - is the leading cause of disability, affecting both physical and psychological parameters. ${ }^{24}$ Respondents with KOA+ in this study had significantly higher SF-MPQ values in terms of total, sensory, and affective scores than respondents with KOA. KOA+ tends to be accompanied by difficulties such as pain while at rest and/or spontaneous pain. These are reported to be symptoms of pain sensitization due to deterioration of internal pain inhibitory systems (eg, a descending neural pathway) associated with persistent pain and myofascial pain; each could play a role in pain and disability of patients with KOA. ${ }^{25,26}$

Respondents with $\mathrm{KOA}+$ fared worse than respondents with KOA across all the AIMS2-SF domains, thus showing that $\mathrm{QoL}$ of the former was significantly worse than the latter.
Among all the domains, both groups reported highest QoL impairment with respect to social interaction associated with movements. However, these differences in QoL were not accompanied by significant differences in TSQM-9 Global, Effectiveness, and Convenience scores across the groups. These findings should be interpreted with caution, because they are inconsistent with a prior patient-reported observational study ${ }^{27}$ and a systematic review, ${ }^{28}$ both of which showed that treatment satisfaction correlated with better QoL. Since treatment satisfaction scores were largely driven by whether the respondents' expected post-medication pain levels matched reality, it is possible that the respondents adjusted their treatment outcome expectations according to the extent of their OA (ie, those with KOA+ may have expected more relief than those with KOA), such that satisfaction did not differ even if the clinical effects of the medication did. At the same time, QoL is likely to be independent of such adjusted expectations from treatment, thereby revealing a significant association with knee pain. Hence, additional research may be needed to understand how treatment satisfaction relates to QoL in the current study's patient population. 
OA pain in both respondents with $\mathrm{KOA}$ and $\mathrm{KOA}+$ was primarily managed with a patch/ointment or intraarticular hyaluronic acid injections, in line with Japanese guidelines for OA treatment. ${ }^{29}$ Respondents with KOA+ used oral medications more frequently than did respondents with KOA, the latter of whom tended to be prescribed hyaluronic acid injections more frequently, probably due to the localized pain. Among oral medications, non-steroidal anti-inflammatories were prescribed more frequently than acetaminophen, possibly due to toxicity and lack of efficacy as reported recently. ${ }^{30}$

The study has a few limitations. Respondents were recruited from two online research platforms, which could have led to selection bias within and across the corresponding survey samples. However, these research panels utilize safeguards to prevent duplicate participation and minimize inclusion of respondents providing inaccurate reporting. Since data were derived from a cross-sectional survey, it cannot be confirmed whether treatment dissatisfaction was caused by the factors identified in the current study. Moreover, the survey was patient-reported and was hence susceptible to recall bias. However, the strength of the study is that data were sought online and outside of the health care setting, presumably making the respondents feel more at ease answering questions regarding treatment satisfaction than they would have been in the presence of a health care professional. Respondents were asked to rate their pain in the past day, week, and month, with corresponding accuracy and precision potentially reduced with increased duration. Although an attempt was made to include only respondents with KOA and to group respondents based on pain in other sites, in the absence of radiographic examinations, it is difficult to confirm OA in each reported site. However, our results are supported by a study finding that patient-reported surveys were almost on par with American College of Radiology standards in identifying hip and KOA cases..$^{31}$ Moreover, $\mathrm{OA}$ is the most common cause of knee pain in people aged 50 years or above. Based on a large-scale epidemiological study in Japan, there is a strong correlation between knee pain and radiographic KOA with pain in patients with KellgrenLawrence (KL) scores $\geq 2$. Also, approximately $10 \%$ of men and $20 \%$ of women without radiographic $\mathrm{KOA}(\mathrm{KL}=0 / 1)$ had knee pain. ${ }^{32}$ Treatment regimens were not confirmed with the respective respondents' health care provider. Additionally, treatment satisfaction was assessed for all current OA pain medications. Therefore, the effect and contribution of each medication among all received treatments are unknown. Since QoL comparisons were conducted without controlling for potential confounders, some of the QoL differences may be attributable to differences in measured (demographic and clinical characteristics) and unmeasured differences between those with $\mathrm{KOA}$ and $\mathrm{KOA}+$. For example, CCI scores were higher among those with KOA+ than those with KOA, which likely also contributed to poorer QoL. Finally, the survey may not be representative of the actual KOA population in Japan, since this survey was limited to persons with Internet access. Also, very frail elderly patients may not have been able to physically complete and submit the survey or they may not have been able to do so because of a lack of computer literacy.

\section{Conclusion}

Respondents with $\mathrm{KOA}+$ are more likely to experience consistent and long-lasting pain, experience difficulty with sleeping or resting due to their knee pain, and, overall, have worse QoL than respondents with KOA. However, all domains of TSM revealed low satisfaction across both the groups, indicating that current treatments may not be providing adequate outcomes for patients with KOA, regardless of severity. Strong potential predictors of TSM included the following: expected pain levels matching reality post-medication, change in pain pre- to post-medication, and reported lower levels of pain premedication, suggesting that treatments that manage pain better and align with patients' expectation of pain management may be especially beneficial in improving treatment satisfaction. This is especially important as patients age, their conditions worsen, and their need for pain alleviation increases.

\section{Abbreviations}

AIMS2-SF, Arthritis Impact Measurement Scale 2-Short Form; BMI, body mass index; CCI, Charlson comorbidity index; GLM, generalized linear models; IQR, interquartile range; KOA, knee osteoarthritis; KOA+, knee osteoarthritis and additional painful sites; NRS, Numerical Rating Scale; OA, osteoarthritis; OARSI, Osteoarthritis Research Society International; QoL, quality of life; SF-MPQ, Short-Form McGill Pain Questionnaire; TKA, total knee arthroplasty; TSM, treatment satisfaction for medication; TSQM-9, Treatment Satisfaction Questionnaire for Medication-9.

\section{Acknowledgments}

The authors acknowledge Ramu Periyasamy, Ph.D. and Leo J Philip Tharappel from Indegene for assistance with literature review and writing. Eli Lilly Japan funded this manuscript and the study on which it was based. 


\section{Author contributions}

$\mathrm{KU}, \mathrm{NS}, \mathrm{KS}$, and $\mathrm{HE}$ designed the study, contributed to data interpretation, and critically revised the manuscript. AG and SRC advised in designing the study, oversaw data collection, analyzed and interpreted data, and edited the manuscript. TM advised in designing the study and contributed to interpretation and manuscript revision. All authors read and approved the final manuscript and agree to be accountable for all aspects of the work.

\section{Disclosure}

At the time of the study, KU, NS, KS, and $\mathrm{HE}$ were full-time employees of Eli Lilly Japan, while AG and SRC were fulltime employees of Kantar Health, which conducted the study with funding from Eli Lilly Japan. TM reports no conflicts of interest in this work.

\section{References}

1. Thysen S, Luyten FP, Lories RJ. Targets, models and challenges in osteoarthritis research. Dis Model Mech. 2015;8(1):17-30.

2. Woolf AD, Pfleger B. Burden of major musculoskeletal conditions. Bull World Health Organ. 2003;81(9):646-656.

3. Yoshimura N, Muraki S, Oka H, et al. Accumulation of metabolic risk factors such as overweight, hypertension, dyslipidaemia, and impaired glucose tolerance raises the risk of occurrence and progression of knee osteoarthritis: a 3-year follow-up of the ROAD study. Osteoarthritis Cartilage. 2012;20(11):1217-1226.

4. Garner M, Alshameeri Z, Khanduja V. Osteoarthritis: genes, naturenurture interaction and the role of leptin. Int Orthop. 2013;37(12): 2499-2505.

5. McAlindon TE, Bannuru RR, Sullivan MC, et al. OARSI guidelines for the non-surgical management of knee osteoarthritis. Osteoarthritis Cartilage. 2014;22(3):363-388

6. Kirchner M, Marshall D. A double-blind randomized controlled trial comparing alternate forms of high molecular weight hyaluronan for the treatment of osteoarthritis of the knee. Osteoarthritis Cartilage. 2006; 14(2):154-162.

7. French HP, Keogan F, Gilsenan C, Waldron L, O'Connell P. Measuring patient satisfaction with exercise therapy for knee osteoarthritis: evaluating the utility of the physiotherapy outpatient survey. Musculoskeletal Care. 2010;8(2):61-67.

8. Kuroda Y, Matsumoto T, Takayama K, Ishida K, Kuroda R, Kurosaka M. Subjective evaluation before and after total knee arthroplasty using the 2011 Knee Society Score. Knee. 2016;23(6):964-967.

9. Nakano N, Matsumoto T, Ishida K, Tsumura N, Kuroda R, Kurosaka M. Long-term subjective outcomes of computer-assisted total knee arthroplasty. Int Orthop. 2013;37(10):1911-1915.

10. Nakahara H, Okazaki K, Mizu-Uchi H, et al. Correlations between patient satisfaction and ability to perform daily activities after total knee arthroplasty: why aren't patients satisfied? J Orthop Sci. 2015; 20(1):87-92.

11. Harvie P, Sloan K, Beaver RJ. Computer navigation vs conventional total knee arthroplasty: five-year functional results of a prospective randomized trial. J Arthroplasty. 2012;27(5):667-672.

12. Bin Abd Razak HR, Tan CS, Chen YJ, et al. Age and Preoperative Knee Society Score Are Significant Predictors of Outcomes Among Asians Following Total Knee Arthroplasty. J Bone Joint Surg Am. 2016;98(9): $735-741$.

13. Ledford CK, Millikan PD, Nickel BT, et al. Percent Body Fat Is More Predictive of Function After Total Joint Arthroplasty Than Body Mass Index. J Bone Joint Surg Am. 2016;98(10):849-857.
14. Maratt JD, Lee YY, Lyman S, Westrich GH. Predictors of Satisfaction Following Total Knee Arthroplasty. J Arthroplasty. 2015;30(7): $1142-1145$

15. Raja R, Dube B, Hensor EM, Hogg SF, Conaghan PG, Kingsbury SR. The clinical characteristics of older people with chronic multiple-site joint pains and their utilisation of therapeutic interventions: data from a prospective cohort study. BMC Musculoskelet Disord. 2016;17:194.

16. Brosseau L, Taki J, Desjardins B, et al. The Ottawa panel clinical practice guidelines for the management of knee osteoarthritis. Part one: introduction, and mind-body exercise programs. Clin Rehabil. 2017;31(5): 582-595.

17. Zhang W, Moskowitz RW, Nuki G, et al. OARSI recommendations for the management of hip and knee osteoarthritis, Part II: OARSI evidence-based, expert consensus guidelines. Osteoarthritis Cartilage. 2008;16(2):137-162.

18. Hawker GA, Mian S, Kendzerska T, French M. Measures of adult pain: Visual Analog Scale for Pain (VAS Pain), Numeric Rating Scale for Pain (NRS Pain), McGill Pain Questionnaire (MPQ), Short-Form McGill Pain Questionnaire (SF-MPQ), Chronic Pain Grade Scale (CPGS), Short Form-36 Bodily Pain Scale (SF-36 BPS), and Measure of Intermittent and Constant Osteoarthritis Pain (ICOAP). Arthritis Care Res (Hoboken). 2011;63(Suppl 11):S240-S252.

19. Bharmal M, Payne K, Atkinson MJ, Desrosiers MP, Morisky DE, Gemmen E. Validation of an abbreviated Treatment Satisfaction Questionnaire for Medication (TSQM-9) among patients on antihypertensive medications. Health Qual Life Outcomes. 2009;7:36.

20. Guillemin F, Coste J, Pouchot J, Ghézail M, Bregeon C, Sany J. The AIMS2-SF: a short form of the Arthritis Impact Measurement Scales 2. French Quality of Life Rheumatology Group. Arthritis Rheum. 1997;40(7):1267-1274.

21. Gimenez S, Armada B, Iturralde Iriso J, Ginel Mendoza L, FernándezMorales B. Clinical management of patients with hip and knee osteoarthritis: patient satisfaction with treatment switch. Rheumatol Int. 2014;34(6):823-832.

22. Felson DT, Niu J, Quinn EK, et al. Multiple Nonspecific Sites of Joint Pain Outside the Knees Develop in Persons With Knee Pain. Arthritis Rheumatol. 2017;69(2):335-342.

23. Kendzerska T, Jüni P, King LK, Croxford R, Stanaitis I, Hawker GA. The longitudinal relationship between hand, hip and knee osteoarthritis and cardiovascular events: a population-based cohort study. Osteoarthritis Cartilage. 2017;25(11):1771-1780.

24. Heidari B. Knee osteoarthritis prevalence, risk factors, pathogenesis and features: Part I. Caspian J Intern Med. 2011;2(2):205-212.

25. Fingleton C, Smart K, Moloney N, Fullen BM, Doody C. Pain sensitization in people with knee osteoarthritis: a systematic review and meta-analysis. Osteoarthritis Cartilage. 2015;23(7):1043-1056.

26. Dor A, Kalichman L. A myofascial component of pain in knee osteoarthritis. J Bodyw Mov Ther. 2017;21(3):642-647.

27. Conaghan PG, Serpell M, McSkimming P, Junor R, Dickerson S. Satisfaction, Adherence and Health-Related Quality of Life with Transdermal Buprenorphine Compared with Oral Opioid Medications in the Usual Care of Osteoarthritis Pain. Patient. 2016;9(4):359-371.

28. Shan L, Shan B, Suzuki A, Nouh F, Saxena A. Intermediate and longterm quality of life after total knee replacement: a systematic review and meta-analysis. J Bone Joint Surg Am. 2015;97(2):156-168.

29. Kawaguchi H. International and National Guidelines of Osteoarthritis Treatment. Jpn J Joint Dis. 2016;35(1):1-9.

30. Machado GC, Maher CG, Ferreira PH, et al. Efficacy and safety of paracetamol for spinal pain and osteoarthritis: systematic review and metaanalysis of randomised placebo controlled trials. BMJ. 2015;350:h1225.

31. Ratzlaff C, Koehoorn M, Cibere J, Kopec J. Clinical validation of an Internet-based questionnaire for ascertaining hip and knee osteoarthritis. Osteoarthritis Cartilage. 2012;20(12):1568-1573.

32. Muraki S, Oka H, Akune T, et al. Prevalence of radiographic knee osteoarthritis and its association with knee pain in the elderly of Japanese population-based cohorts: the ROAD study. Osteoarthritis Cartilage. 2009;17(9):1137-1143. 
Clinical Interventions in Aging

\section{Publish your work in this journal}

Clinical Interventions in Aging is an international, peer-reviewed journal focusing on evidence-based reports on the value or lack thereof of treatments intended to prevent or delay the onset of maladaptive correlates of aging in human beings. This journal is indexed on PubMed Central, MedLine,

CAS, Scopus and the Elsevier Bibliographic databases. The manuscript management system is completely online and includes a very quick and fair peer-review system, which is all easy to use. Visit http://www.dovepress. $\mathrm{com} /$ testimonials.php to read real quotes from published authors.

Submit your manuscript here: http://www.dovepress.com/clinical-interventions-in-aging-journal 